\title{
Factors Influencing the Acquisition of Mandarin Chinese as a Second Additional Language Focusing on Phonetics
}

\author{
Norma Margaret Nel* \\ Department of Psychology of Education, College of Education, University of South Africa \\ ORCID:0000-0003-4900-446X
}

\author{
Soezin Krog \\ University of South Africa, Department of Early Childhood Education and Development, \\ College of Education, University of South Africa
}

ORCID:0000 0001-8075-3042

\begin{tabular}{l}
\hline \hline Article history \\
\hline Received: \\
01.02 .2020 \\
Received in revised form: \\
15.06 .2020 \\
Accepted: \\
01.07 .2020 \\
Key words: \\
\hline Mandarin; \\
Phonetics; \\
Second additional language \\
(SAL); \\
Second Language Acquisition \\
(SLA)
\end{tabular}

Mandarin has been added to the list of second additional languages (SAL) that South African learners can choose from. The researchers proactively conducted research pertaining to SAL (Mandarin) since it is a dynamic phenomenon in South Africa. The research question was formulated as follows: Do factors such as 1) phonemic differences between learners' mother tongue and Chinese, 2) learners' cognitive styles and 3) learners' abilities of singing and tone imitation, influence non-native learners of Mandarin (as a SAL) in South Africa to learn Chinese phonetics? We foresee that our findings will contribute to the learning and teaching of Mandarin (SAL) in South African schools. This article serves as the second in a series of three articles, as a mixed method (quan-qual) design was called for. Hypotheses were formulated and statistics presented to either accept/reject them. We gleaned the conclusions of the quantitative part of the research as a springboard and focused on the qualitative findings derived from interviews, observations and a literature review, which enabled us to identify and arrange the (quan-qual) data according to categories and themes. The quantitative data revealed that there was no significant correlation between learners' learning preferences and Chinese phonetics performances; singing and tone imitation abilities contributed to initial consonant pronunciation and tone 3 pronunciation; learners with musical abilities performed better at reading the Pinyin phonics table; identified initial consonants, multi-vowels and whole syllables were challenging to read; tone 3 was the most challenging, tone 1 was the easiest and tones 2, 3 and 4 were mispronounced as tone 1 . From the qualitative data two themes emerged, namely the challenges of learning and teaching 
Chinese phonetics, and aspects to consider when learning Chinese phonetics. Based on the integrated quan-qual findings, we were able to contribute to the existing body of knowledge on this topic.

\section{Introduction}

Plumb (2016: 48, 59) states that there is "speculation that Mandarin Chinese is becoming a mainstream global language to the point of becoming a lingua franca". This may well be true in certain contexts, such as China and East Asia, but not in others. It is not likely that Mandarin Chinese will earn global lingua franca status, despite its importance escalating - that is because it needs to compete with English as the current global lingua franca. Seeing that this country is part of BRICS (Brazil, Russia, India, China, South Africa) it would be beneficial for these countries to seize the great opportunities this partnership offers for research in priority research areas such as learning mobility and "collaboration in all disciplinary areas", to contribute to "a common/comparative knowledge base", and for economic consolidation and sociopolitical reasons (Rensburg, Motala \& David, 2015: 817-818). Against this background we deem it a good opportunity to embark on research which may have an impact on BRICS countries, namely the introduction of Mandarin as a second additional language (SAL) in South African schools.

Since Mandarin has been introduced in South African schools as an SAL (DBE, 2015), it is apt to conduct research into the learning behaviours of learners of Mandarin as a foreign language, the reason being that "Chinese is one of the most difficult languages for speakers from the IndoEuropean language family to learn" (De Man, 2017: 125). Curriculum writers have particular demands regarding the specific nature of Mandarin as a Sino-Tibetan language: "Learning Chinese as a non-native is a challenging task, especially for learners with an alphabetic L1 [first language] background; one of the biggest hurdles is the large set of Chinese characters and the opaque nature of the Chinese writing system" (Lü, 2017).

Mandarin teachers need to find ways to use "effective learning tools and programs to better serve learners' needs" (Sung \& Wu, 2011: 684). Therefore, where teachers can help learners to learn Mandarin and the culture it represents, they will be preparing them to become global citizens and to "advance in the $21^{\text {st }}$ century" (De Man, 2017: 160). It is vital to focus on the pronunciation of Chinese, as it is difficult to acquire due to the different tones - an aspect of Standard Chinese (SC) pedagogy which receives little attention. Tř́sková (2017: 10) opines that teachers may lack sufficient training in phonetics/phonology for them to teach the sophisticated treatment of topics - they need to understand that the underlying principles of the Chinese sound system help one to communicate more effectively. Worryingly, researchers may be disinterested in the pedagogical concerns, hence calls for SC pronunciation instruction to be lined up with second language acquisition (SLA) research findings, and to include phonetics and phonology in teaching materials and the training of teachers.

In the light of the above, the fundamentals of pronunciation should be acquired right at the beginning of L2 (second language) studies, as the new phonological system of the L2 is established in the mind of the learner. The speech production errors which the beginner makes need to be attended to, otherwise they become fossilised because of bad pronunciation habits being perpetuated which may prevent the interlanguage phonology or phonetics from developing any further. It is thus important that a teaching methodology of L2 pronunciation be deliberate and carefully planned in steps (in succession), together with well-prepared coordination with other teaching objectives - explicit teaching is needed for children. It is more 
difficult to assess and correct pronunciation errors than it is to correct grammatical errors. A learner is equipped through a certain level of phonological/phonetic awareness with concepts and devices to control progress after formal education (Tř́sková, 2017: 4, 8-9).

Trísková (2017:13) advises the authors of textbooks to undergo some sort of training in SC phonology and phonetics, and gain insight into research literature. A learner needs to set aside the familiar phonology of the L1 and create a "phonological sieve" for the L2, when learning L2 pronunciation. This sieve enables learners to distinguish between the L2 sounds necessary for phonemic categories and those which are only "within-category phonetic variations". Pinyin phonology enables the acquisition of the SC sound structure. When learning SC consonants and vowels, learners need to learn new articulations, not replace SC sounds with similar L1 sounds that are familiar to them. New sounds can be learnt by making use of phonetic descriptions which clarify the articulatory or acoustic features, hence places of articulation (e.g., alveolar) and manners of articulation (e.g., fricative for consonants) need to be learnt. Other terms such as voiced vs voiceless are also necessary to know, along with terms regarding vowels, such as front-back, nasalisation etc. All of this knowledge helps learners to recognise the differences between the L1 and L2 sounds, and enables them to control the phonetic details of articulation. It also helps the teacher to correct errors. Diagrams of articulatory organs and palatograms are very useful for teaching difficult sounds (e.g., they can demonstrate that SC palatal consonants such as $j, q$ and $x$ are alveolopalatal) (Tř́sková, 2017: 16-17).

In this paper, the authors aim to identify factors which play a role in learning the Chinese characters and, in so doing, to arrive at new thinking in respect of teaching and learning the language. Although research can be conducted on an array of aspects when learning Chinese characters, we have chosen to focus on those factors which influence the learning of Chinese phonetics by non-native South African learners learning Mandarin as their SAL. The subresearch questions (quantitative and qualitative) emerged from the main research question: Do factors such as 1) phonemic differences between learners' mother tongue and Chinese, 2) learners ' cognitive styles and 3) learners' abilities of singing and tone imitation, influence nonnative learners of Mandarin (as a SAL) in South Africa to learn Chinese phonetics?

The rest of this article is presented as follows: we investigate the SLA theories applicable to this study; discuss the Chinese and alphabetic orthographies; look at how to learn Chinese characters using Pinyin; and study the status of Mandarin taught as an SAL within the South African context. Thereafter the selected research methodology is discussed. The article ends with a discussion of the findings, conclusions and recommendations. This article is structured in such a way as to explain the logic, progression and rationale of the foregoing study, to illustrate the appropriateness and value of a mixed-methods investigation. A summary of the quantitative findings is provided in an effort to expand on the findings of the qualitative part of the research, thus it forms the second part of a series of articles emerging from the mixedmethod research. Thus, the purpose statements and research questions which "specify the quantitative and qualitative aspects of the investigation" are included, which ultimately aim to "produce a more comprehensive answer to the research question" as opposed to what a single method would (Dörnyei, 2007: 303).

\section{SLA theories}

It is important to note that "research findings should be consistently integrated into L2 pedagogy" (Tř́sková, 2017: 9). El-dali (2019: 1488) points out that "theories of how second languages are learned have been approached from a variety of perspectives: sociolinguistic, 
educational, neurolinguistic, psycholinguistic, and linguistic.” El-dali (2019: 1489) states that linguistic theories often assume that it is through the human mind that language is acquired, which is "different from any other knowledge". Cognitive approaches regarding the acquisition of L2 are considered "a complex cognitive skill ... a mental process leading through structured practice of various component subskills to automatization and integration of linguistic patterns" (El-dali, 2019: 1489).

SLA theories include Krashen's Monitor Model (an overall theory of SLA) ( 1970 ); interlanguage theories (which describe the linguistic stage L2 learners are at); universal grammar theories such as that of Chomsky $(1969,1980,1986)$, who claims "there are certain principles that form the basis on which knowledge of language develops". Cognitive theories view second-language learning as the acquisition of complex cognitive skills; the multidimensional model claims that the target language acquired depends on one's development stand and social-psychological orientation; the acculturation/pidginisation theory of SLA is "greatly affected by the degree of social and psychological distance between the learners and the target-language culture" (Gitsaki 2018: n.p.). Gitsaki (2018) found that even though theories try to explain how language is acquired, each theory gives a different insight in the SLA process. All of the mentioned theories regard SLA as a "gradual process ... to progress towards the target language going through various stages of development".

Interestingly, if the rules of a learners' mother tongue are similar to the target foreign language $\mathrm{s} /$ he aims to learn, it will facilitate the learning of the foreign language. If there are great differences it will act negatively, hindering the learning of the foreign language. Language transfer during "the process of building a second language system" (Wang \& Xiang, 2016: 2209) occurs when learners regard the beginning point as their mother tongue. Where similarities and differences are compared between the native language and target language, the learner can transfer the forms and rules of the native language to the second language and, in this way, influence the acquisition of the second. Negative transfer takes place on all levels of language structure, for example the phonetic level, where the learner's foreign accent is evident when learning the foreign language (Wang \& Xiang, 2016: 2208-2210). Yan and Matthews (2017: 2) explain that language transfer usually takes place from the dominant to the nondominant language. This calls for a phonological comparison to be made between the native and the target language (Lai, 2009: 1267).

Learning Chinese as an L1 may offer "broad phonological sensitivity benefits" (enhanced by using Pinyin) as well as "strong visual-spatial skills, perhaps via visuo-motor practice" (McBride, 2016: 540). "[T] phonological coding system and of Chinese, both of which may be helpful for setting the stage for subsequent learning" (McBride, 2016: 541). By copying the Chinese characters - a major part of the learning process - learners cultivate orthographic awareness, linking "visual symbols, phonological representations and semantics" McBride (2016: 542). Through the use of motor programmes, long-term motor memories for the characters are developed, which means many copying exercises are required where stroke order is very important - copying is thus emphasised as a "central instructional technique[ ] for teaching Chinese" (McBride, 2016: 542). A pure copying ability can be a link to successful Chinese literacy acquisition. Researchers have found that Chinese children are superior in visual skills (which help them to learn to read Chinese) when compared to learners who learn the alphabetic orthography, but they are similar in terms of other cognitive measures (McBride, 2016: 542-543). 


\section{Chinese and alphabetic orthographies}

Whilst some writing systems are alphabetic, where each letter "roughly represents a phoneme", others are logographic, where "each character represents a morpheme" (Suk-Han Ho \& Bryant, 1997: 276).. The question is whether learners "learn to read different orthographies in different ways" (Suk-Han Ho \& Bryant, 1997: 276). Important to note is that phonological awareness is not as important for learning to read Chinese as it is for learning to read alphabetic orthographies (McBride, 2016: 545).

Amongst others, semantic radicals of Chinese characters do not have any analogy to alphabetic orthographies; unreliable phonological cues and the reliability on lexical compounding for word building most importantly requires morphological awareness for the development of early reading. In addition, simplified and traditional scripts have different characteristics, strengths and weaknesses, when teaching and learning Chinese. When learning Chinese, segmental and suprasegmental phonological sensitivity may be strengthened and even basic visual skills may be promoted and have cognitive advantages (McBride, 2015: 523). Homophones (similarsounding words with different spelling, e.g. tide and tied) and homographs (similar spelling, different meanings, e.g. bank of a riverbank and bank where you draw money), are pivotal in Chinese characters. Thus it is important to know which characters indicate homophones and which homographs (Li \& McBride-Chang, 2013). Chinese characters and words relate to meaning. Phonetic as well as semantic radicals are important for identifying characters. With multi-character words it is important to associate the characters with one another, which requires lexical compounding. Characters and words are acquired via different acquisition processes, and there are different developmental associations between them (Li \& McBrideChang, 2013: 49).

To learn Chinese words, three concepts are related namely the radical, character and word. A radical is a unit made up of strokes in an unbroken line, performed as a single movement - it is the smallest part of a character. Eight basic strokes are produced using different movements, as illustrated in figure 1.

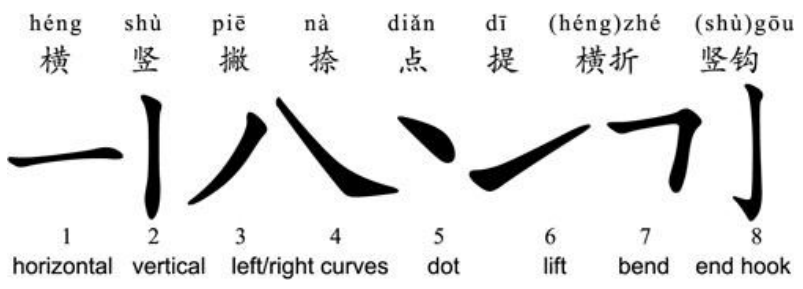

Figure 1: The eight basic strokes used to write Chinese characters

Whole characters are formed by using two or more radicals (so-called compound radicals). Phonetic radicals are found on the right side of a left-right compound character and indicate the sound. On the left is the semantic radical which indicates the meaning and is not pronounced in the character. An example of this is the character for "mom", 妈, which is pronounced as "mā". This is a compound character, comprising the radical 女 (pronounced "nü̆") on the left, which means "female", and the character 马 (pronounced "mă") on the right, from which 妈derives its sound. Note that this left-right approach is not all encompassing: sometimes a topdown approach is used instead, for example, the character for dad, 爸 (“bà”), which consists of 父 ("fü") on the top, meaning "father" and 巴 ("bā") at the bottom, indicating the sound. In certain cases, the phonetic radical may be found on the left side of the character.

One Chinese character "maps onto a single syllable" (McBride, 2016: 527), which may also be 
a single morpheme. Words can comprise more than one character or one character with its own meaning. An example of a single-character word is 我, meaning the pronoun "I" or "me". An example of a multi-character word is 手机, which consists of two characters that, when combined, mean "cell phone", but have different meanings when separated, namely, 手 means "hand" and 机means "machine".

Although all characters take up the same square space on the page, they are not grouped according to words. Chinese is thus read by means of characters (McBride, 2016: 526). Whereas words in English writing conventions are well defined (letter strings are bound by spaces), which act as inputs for reading, Chinese words vary from one to as many as four characters, each mapping a syllable-morpheme. Noted that words comprising four characters are often idioms that are used in the same way as phrases: for example, 九 “nine”, 牛 “cow”, 一 “one”, 毛 "hair", when put together, form an idiom meaning "a single hair from nine cows, i.e., comparatively tiny and insignificant". Some words are derived as direct translations from English based purely on sound, for example: coffee = 咖啡 “kā fềi”; sofa = 沙发 “shā fā".

A character can be a one-character word or the first character in a two- or three-character word, which makes word identification processes more complex as it requires "character string parsing and context dependent character-to-word matches" (Perfetti, Cao \& Booth, 2013: 8). Although word identification is universal for reading, the processes that let it happen are different. Phonology is thus regarded as a universal component of reading, but the procedures used to let it happen depend on the writing system's linguistic units (Perfetti, Cao \& Booth, 2013: 8-9).

The universal phonological principle (UPP) unites Chinese and alphabetic writing systems at a functional principle level. Where Chinese maps graphs to syllabic morphemes, the alphabet maps graphs to phonemes. It can be concluded that both systems involve phonology as part of reading Chinese characters and English words, but they are significantly different. The Chinese orthographic form is more significant while phonology is less supportive than in alphabetic writing. Conclusively, phonology, orthography and morphology (being lexical constituents) are universal and thus result in high general descriptions of word reading in Chinese and alphabetic writing, where reading is initiated universally through orthography. When orthographic inputs, meaning activation and selection activate phonology (universally), these are the outcomes of reading (Perfetti et al., 2013: 8-11).

The traditional vocabulary teaching method in Chinese primary schools has been replaced by the phonics method, with the aim of developing phonemic awareness by teaching the correspondence between sounds and the spelling patterns (graphemes) which represent them. By teaching phonics, beginning readers are enabled to decode words by means of sounding them out/blending the sound-spelling patterns ( $\mathrm{Li}, 2019: 99) . \mathrm{Li}$ (2019: 103) asserts that, through phonics, English pronunciation, vocabulary and reading are effective ways for primary learners to learn. Phonics also enables the reinforcement of positive transfer and the facilitation of second-language learning.

\section{How to learn Chinese characters using Pinyin (Chinese phonic system)}

"Unlike phonetic alphabets, the Chinese language is created and indicated by pictographic symbols, which are endowed with a more explicit pattern of implication on the mechanism of metaphorisation" (Xianka Ren, 2014: 157). Xianka Ren (2014: 162) postulates that the gateway for beginner learners of Chinese is pictographic characters. There are six , 
called Liu Shu - four function as approaches for character invention and two for character application. All six represent the mechanism of metaphorisation. An example is the pictophonetic script, which is an approach to create characters to help learners memorise groups of characters, because of the use of radicals. Picto-phonetic characters have two components, namely a radical (pictographics allowing for easy recognition and recall) and a phonetic element (the original pronunciation of the characters). Radicals help to classify characters, as they have a relation with a same idea/concept using the same radical which "indicates that idea or concept" (Xianka Ren, 2014: 162). Characters with the same radical "natively belong to the same field. The radical works as the foundation of the classification of characters" (Xianka Ren, 2014: 162). "The combination of the radical (particularly with its meaning) with the meaning of the character derives from the application of metaphorization" (Xianka Ren, 2014: 163). Thus, learners can memorise characters better, as most are "diagram-based or pictograms" (Xianka Ren, 2014: 163). "...the application and understanding of the image imitation is based on the metaphorical connection between the concrete object and the abstract written icons" (Xianka Ren, 2014: 163). “... the establishment and utilization of metaphorization in pedagogical practice is the key to improving Chinese character study and writing among English-speaking students" (Xianka Ren, 2014: 163).

Several new approaches are being used to teach Chinese characters, such as the Pinyin system. Every single written character corresponds to a spoken syllable, and each syllable/character has meaning, either the word or the morpheme which makes up a multi-character word. For example, 奖状 (“jiăng zhuàng”) is a multi-character word that means "certificate of merit". The first character, 奖, can be used as a single-character noun meaning prize/reward. However, the second character, 状, is a morpheme which is not commonly used as a stand-alone word, but derives different meanings when combined with different characters.

The Pinyin (phonic) system allows learners to access the characters' sounds and pronunciation, which enables them to attach the sound to the ideograph and meaning. The strategy where the structure and form of characters are taught, teaches the character's main components (morphological and phonetic). A character is taught in three tiers, namely the whole character, the component and the stroke. To illustrate this concept, consider the character for "tree branch", 枝 (pronounced “zhî"). This character can be broken down into its components:

- 木 (“mù”), meaning "tree/wood”, from which it derives its meaning

- 支 (“zhī”), from which it derives its sound.

Individual strokes form the character, for example, 木 is constructed by combining the strokes héng, shù, piě and nà, together and in that order.

Accurate pronunciation of the syllables and analysis of the character involve the following being taught: the stroke order, the shapes of components and the meaning in context, while characters are copied. Other strategies include emphasising the meaning of characters; the association between characters; form and meaning; speech and text association; the use of character clusters; characters possessing the same rhyme and texts that contain character clusters (Tse, Morton, Ki \& Loh, 2007:382-383).

\section{The status of Mandarin taught as a SAL within the South African context}

In light of the complexity of learning Chinese characters (as described above), De Man (2017: 37) predicts that Mandarin Chinese is a language which South Africans will have difficulty learning. Thus, it calls for a "sound and thought-through approach" as well as well- 
informed pedagogical choices suited to our context and that of Mandarin, along with a positive attitude regarding the possibilities it offers South African learners. The DBE (2014:11) states that "learners apply the oral and literacy skills they have already learned in their Home and First Additional Languages to the study of the Second Additional Language". According to Wang and Lemmer (2015: 78-79), learners in South Africa who learn Chinese experience particular challenges. They need to learn the language in an almost non-existent Chinese-speaking community, and there are fewer available Chinese-language resources than those of other foreign languages (e.g., German and Portuguese). Thus, South African learners have limited exposure to Chinese, which is a far cry from a second-language co-existing setting, where the second language co-exists with the dominant language, both languages are spoken by a large percentage of the population, and in a closed environment. An example is a Zulu-speaking learner learning to speak English in South Africa.

De Man (2017: 48), having done a thorough literature survey, concluded that two interrelated factors are essential for analysing and comparing the South African Mandarin Chinese curriculum with another curriculum (e.g., the Australian): 1) the South African curriculum is unique, and 2) the Chinese language is unique. Thus, there is "less space for Mandarin Chinese to enter the South African educational landscape as it needs to compete with other subjects for teaching time and teaching resources such as teachers and learning materials" (De Man, 2017: 118). As De Man notes, should the necessary resources be made available, Chinese in South African schools may be actively promoted. This could be done by being sensitive to the local context and specifying specific language aims when studying Mandarin Chinese. The South African constitution is pro-multilingualism, and the Language in Education Policy (LiEP) emphasises nation-building and cultural diversity, which are strong motivators for Mandarin as a SAL within the South African education curriculum. What complicates the situation, is that education in the home language in practice (with 11 recognised languages in this country), and transitioning to English as the language of learning and teaching (LoLT) in Grade 4 (for which local learners' poor performance is blamed) has prevented Mandarin from competing for space in the local curriculum. De Man (2017) explains that it is envisioned that Mandarin should first be taught in "well-off schools", in the Intermediate Phase (grades 4-6), and after hours. De Man (2017) points out that since school governing bodies consist mostly of parents who play an important role in school governance, and may advocate learning Mandarin in light of globalisation, additional teaching posts will be needed. "We are now in the position to welcome it with grace and wisdom" (De Man, 2017: 123). De Man (2017: 119-121, 123-124) has, however, identified a gap in instructional time and continuity across phases (CAPS Mandarin SAL starts in Grade 4, yet SAL in practice starts in Grade 8) which calls for an adjustment to the curriculum, to better fit the practice.

The CAPS English Generic SAL covers all SALs which, in itself, is not applicable for developing the Mandarin curriculum, as it calls for a language-specific curriculum - here, the reading and writing of Chinese characters need to be reckoned with (De Man, 2017: 125). It is therefore important to consider aspects related to local learners (interested in learning Mandarin), including their exposure to Chinese; to Mandarin only at home; or those who received their primary education in China. Obviously the drop-out rate is higher with learners who have had no Chinese background; time is not indicated in the Intermediate and Senior Phases, and can thus only be offered after school hours; discontinuity from primary school to high school (learners may go to different high schools which do not offer Mandarin) (De Man, 2017: 137, 139-140).

To facilitate the process of introducing Chinese as a foreign language and the Chinese culture 
in different countries, the Council of Chinese Language (Hanban), its Confucius institutes and classrooms which fall under the Chinese Ministry of Education, have been established. By partnering with schools and universities, Hanban is responsible for providing teaching staff and training, as well as teaching materials and equipment (De Man, 2017: 39).

\section{Framework}

Two components are included in reading the Chinese sentence “我很好” (I am fine). First, memory, which means the reader recalls and tries to represent the syllables in his/her mind. Second, pronunciation, in pronouncing the syllables "wǒ hěn hăo" orally, which is problematic for learners learning Mandarin as an L2. Furthermore, pronunciation can be divided into 1) the pronunciation of each phoneme, e.g., the character "我” consists of two phonemes, $/ \mathrm{u} /$ and $/ \mathrm{o} /$, and 2 ) four tones of Chinese pronunciation.

In Chinese it is always very important to pronounce words with the correct tone. In transliterated Chinese, tone markings are written over the central vowels in most syllables. Some syllables have no specific tone, and then no sign is placed above a vowel. In Mandarin Chinese there are four tones:

- The 1 st tone is marked with a line ("a" + "-" = "a" ). This is a high, even and constant tone.

- The 2nd tone is marked with a rising line ("a" + "’" = "á"). This is a rising tone that grows stronger.

- The 3rd tone is marked with a hook ("a" + "v" = "ă"). This tone first falls and fades, then rises and grows strong.

- The 4th tone is marked with a falling line ("a" + "'" = "à"). This is a quickly falling and fading tone.

In unstressed syllables, the tone may be hardly noticeable. In such cases, no marking is placed above a vowel. This may be regarded as "tone zero". The tone will usually end up more or less where the previous syllable ended.

This research starts from Chinese language learners' experience of their mother tongue and other individual differences, and demonstrates three actors that might influence the learning effects: 1) phonemic differences between the learners' mother tongue and Chinese, 2) learners' cognitive styles, and 3) learners' abilities of singing and tone imitation. At the first stage of research, 34 Grade 6 learners, whose first language was English, were selected at a South African school where Mandarin is taught as an SAL. Among the factors presented above, the first relates to phoneme pronunciation, and the second and third to tone pronunciation.

Factor 1. Phonemic differences between learners' mother tongue and Chinese

For factor 1 we have two hypotheses: 1) Learners might pronounce the common phonemes between Chinese and English better than the exclusive phonemes of Chinese (EPC); and 2) learners might confuse EPC with similar phonemes in English, if similarities exist.

Factor 2. Learners' cognitive styles

The hypothesis in Factor 2 is that a higher degree of auditory inclination might form better Chinese pronunciation, especially in the aspect of tones.

Factor 3. Learners' abilities of singing and tone imitation 
The hypothesis for factor 3, is that learners' advantages in singing abilities and tone imitation contribute to their better performance in Chinese tone.

\section{Research methodology}

Any research involving both quantitative and qualitative methods, can be described as mixed methods (Osborne, 2008: 2). Osborne (2008:4) refers to Maxwell and Loomis' (2003) stages of mixed-methods research, which involve determining the purpose, conceptual framework, research questions, methods and validity. Mixed-methods research is used for different purposes, and here it is used in a complementary way "to examine intersecting but different aspects of a phenomenon" (Osborne, 2008: 4). A series of three articles will be written based on mixed-method research which the authors conducted. The first article reports on the quantitative part of the mixed method, this (the second) comprises the qualitative part, and the third reports on the mixed method research, where qualitative data are used to substantiate/elaborate on the quantitative data collected. In this article we discuss the qualitative part of the research, using the conclusions derived from the quantitative study. The emergent nature of the qualitative research design is that we embark on the research process with a "completely open mind and without setting out to test preconceived hypotheses" but to "capture rich and complex details" (Dörnyei, 2007: 37, 38). The research outcome is mainly the researchers' subjective interpretation of the quantitative conclusions, using learner participants and teacher participant interview transcriptions (quotes), observations and a literature review. In this sequential study, one research phase builds on another, thus this research component (qualitative) builds on the "dominant status" of the quantitative component, which is discussed in the framework above (Dörnyei, 2007: 302).

\section{Data-collection tools}

For the quantitative part of the research, the VARK questionnaire was administered to determine learning preferences: How do I learn best? V: visual preference; A: aural; R: $\mathrm{read} /$ write and K: kinaesthetic (see http://vark-learn.com).

Other tests included observations during data collection; a self-rating scale for musical ability (a four-point scale designed by the main researcher to check subjects' singing ability and the ability to imitate tones by asking them five questions on a scale of $1=$ Absolutely disagree to 4 = Absolutely agree); the Pinyin Table Reading Test, where participants are required to read the table aloud (fig. 2). Their accuracy in pronouncing initial consonants (23 in total), simple vowels (6), multi-vowels (18) and whole syllables (16) are counted, and total accuracy is calculated. Finally a Text Reading Test was administered, where participants were required to read a text aloud, to check their performance on the four tones. 


\begin{tabular}{|c|c|c|c|c|c|c|c|}
\hline \multicolumn{7}{|c|}{ 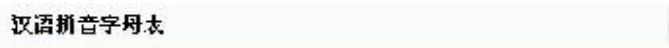 } & \multirow[t]{2}{*}{ 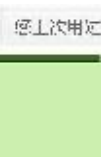 } \\
\hline \multicolumn{7}{|c|}{ 汉语拼音字母表 } & \\
\hline$b$ & $p$ & $\mathrm{~m}$ & $f$ & d & $t$ & $n$ & 1 \\
\hline g & $k$ & h & j & 9 & $x$ & zh & $\mathrm{ch}$ \\
\hline sh & $r$ & $z$ & C & $\mathrm{s}$ & $y$ & W & \\
\hline \multicolumn{8}{|c|}{ 新车表 } \\
\hline a & 0 & e & i & $\mathrm{u}$ & $\ddot{u}$ & ai & ei \\
\hline ui & ao & OU & iv & ie & üe & er & an \\
\hline en & in & un & ün & ang & eng & ing & ong \\
\hline \multicolumn{8}{|c|}{ 整体认读当节 } \\
\hline zhi & $\mathrm{chi}$ & shi & ri & $z i$ & $\mathrm{Ci}$ & si & wu \\
\hline yi & yu & ye & yue & yuan & yin & yun & ying \\
\hline
\end{tabular}

Figure 2: Pinyin table used for this study (http:www.hanyupinyin.cn)

\section{Learner participants}

A number/code was allocated to each of the participants, whose responses were selected, for example: L(learner)5 or LB (a number or letter). The rest of the participants' names were replaced by the word "name".

Table 1: Matching learners with data-collection tools (2018)

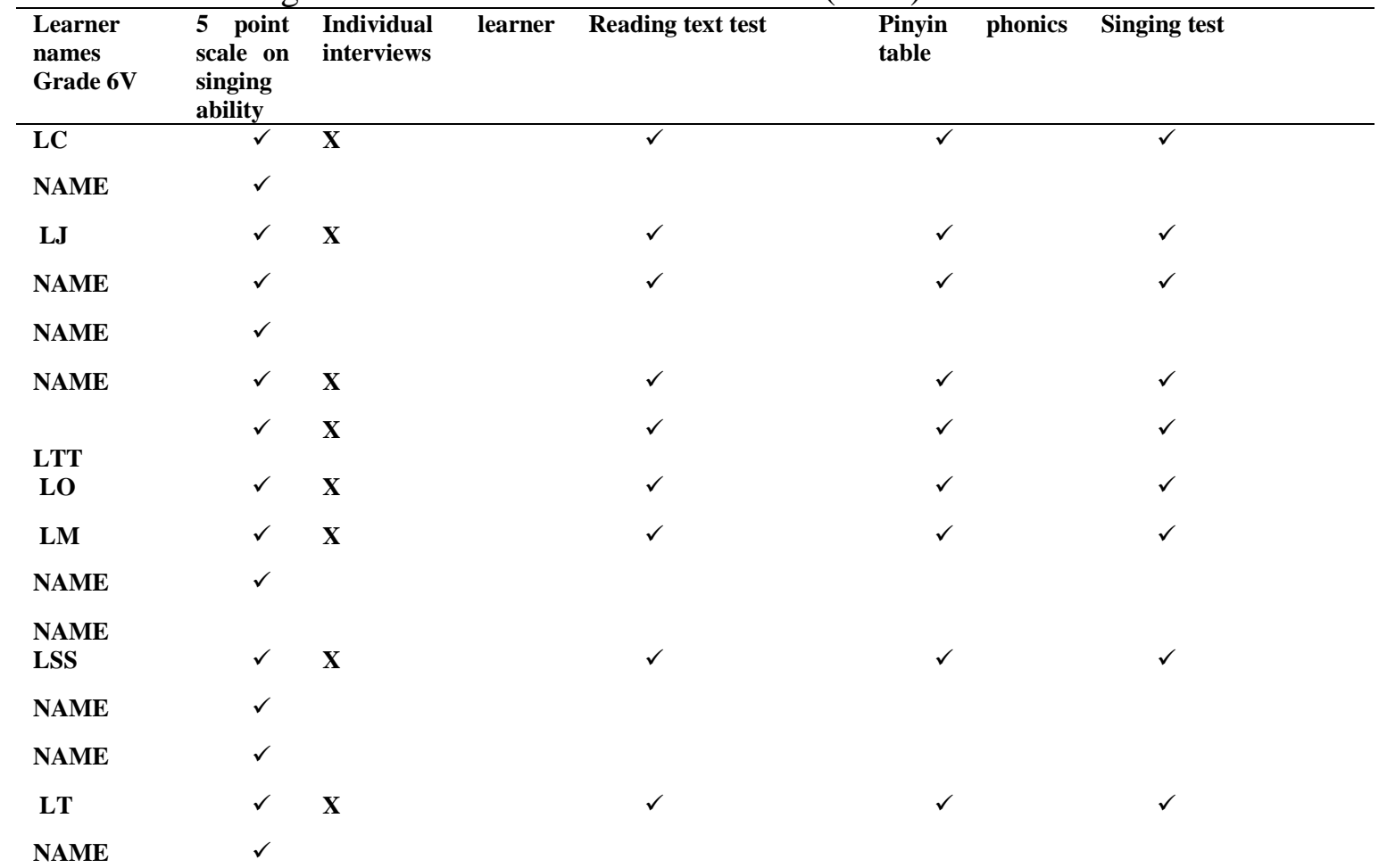




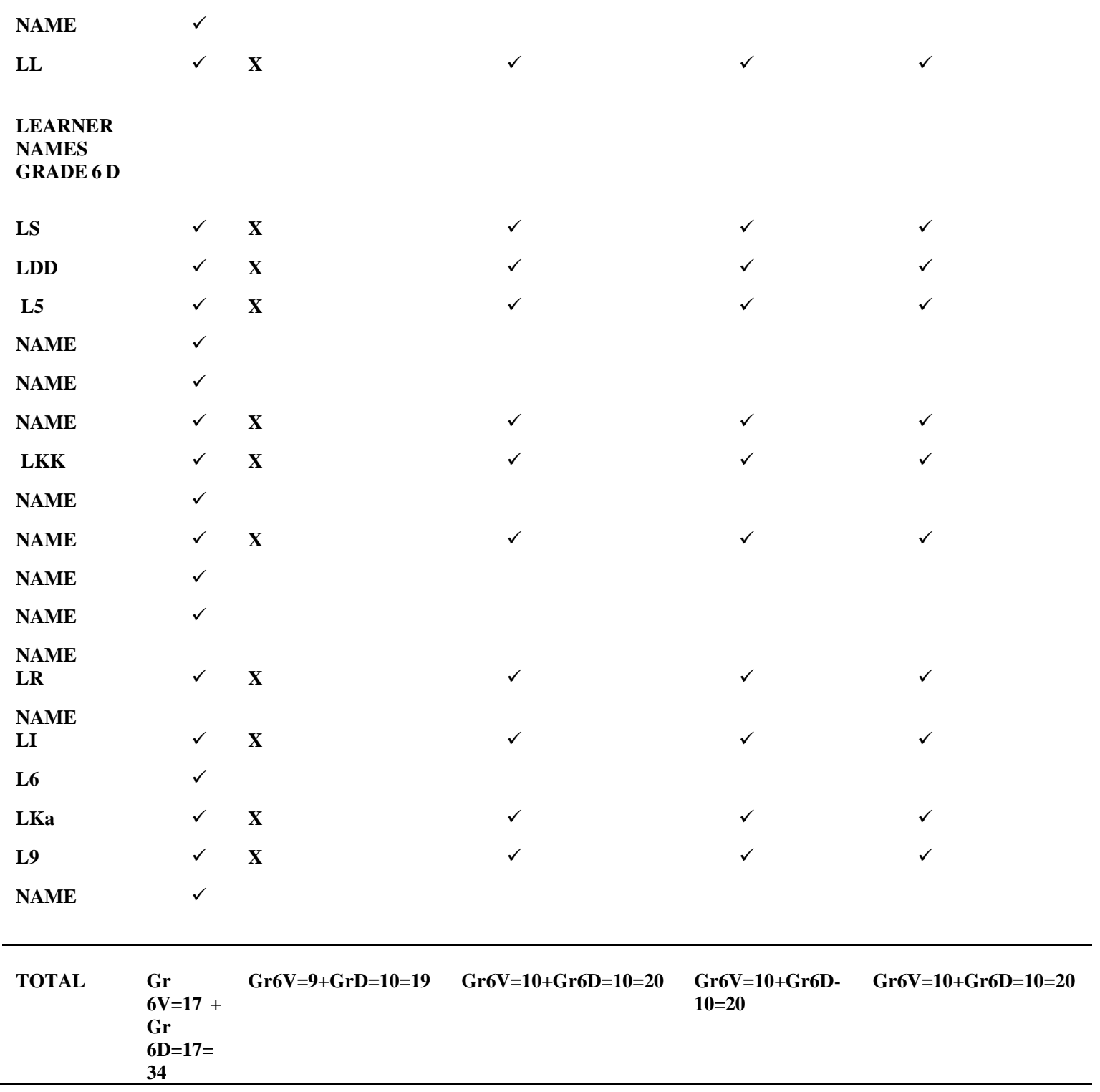

The teacher teaching the learner participants, participated in an individual interview.

\section{Data analysis}

Braun and Clarke (2006: 77-78) argue that thematic analysis "offers an accessible and theoretically flexible approach to analysing qualitative data ... which can potentially provide a rich and detailed, yet complex, account of data". The data corpus encompassed all the collected quantitative and qualitative data. The data set comprised all data items in the data corpus, including the conclusions derived from the correlational and descriptive analyses (quantitative data) and qualitative data derived from the learner interviews, teacher interview, observations and literature verification, to arrive at a particular analysis. Here, that was to identify influencing factors in Chinese phonetics learning in a South African school context. A data extract, which is "an individual coded chunk of data", was identified and extracted from a data item (i.e., an individually collected piece of data in the data set/corpus). The selected extracts were used in the complete analysis as themes were identified, analysed and reported in the data (Braun \& Clarke, 2006: 79). How key the theme is, is not necessarily dependent on quantifiable data (in this study, conclusions from the quantitative data were used). What is crucial is whether it captures that which is important to answer the main research question. 
An inductive approach was chosen to analyse the data, thus the data (transcribed interviews) were read and re-read to arrive at themes (Braun \& Clarke, 2006: 82, 84), sub-themes and categories. The transcribed interview data were coded manually using colour codes, which enabled the researchers to arrange repeated patterns together, to arrive at themes. In so doing, extracts from the raw data were used to "demonstrate that code" (Braun \& Clarke, 2006: 89).

The hypotheses put forward in the framework will be addressed in the conclusions gleaned from the statistical section of the research and integrated in the qualitative part (see below).

\section{Findings}

Key:

- Teacher - T

- Learner interview participants - L (learner)+number (e.g. L2) or L+alphabet letter (e.g. LB)

Table 2: Summary for the quantitative studies on influencing factors in Chinese phonetics learning

Correlational analysis
HYPOTHESIS: A higher degree of auditory inclination might lead to better
Chinese pronunciation, especially in the aspect of tones.

Chinese pronunciation, especially in the aspect of tones.

No significant correlation was found in participants' learning preferences (learning style tendency) and their Chinese phonetics performances. Conclusion: Participants who score higher in aural learning style tendency and/or read/write learning style tendency do not necessarily perform better in reading Pinyin and tones of Mandarin than those who score lower in these two learning style tendencies.

HYPOTHESIS: Learners' advantages in singing abilities and tone imitation contribute to their better performance in Chinese tone.

The score of Self-Rating Scale for Musical Ability (self-rate one's own singing and tone-imitation ability) is significantly correlated with the accuracy of reading initial consonants, but not correlated with the accuracy of reading simple vowels, multi-vowels, whole syllables, or pronouncing tones. Conclusion: Singing and tone imitation abilities contribute to the performance in pronouncing the initial consonant in the Pinyin table.

Number of musical notes imitated correctly in the Singing Test was found significantly correlated with Total Accuracy of Tone Pronunciation in Text Reading Test. And particularly, it significantly correlated with the Accuracy of Tone 3 Pronunciation. Conclusion: Singing and tone imitation ability contributes to the performance of Tone 3 pronunciation.

There is possibility that participants who are musically gifted will perform better in reading the Pinyin Table. Note:

*Those who self-appraised as musically gifted may in fact not be. *The results can also be explained as the correlation between selfconfidence and the performance in reading the Pinyin Table.
Descriptive statistical analysis

HYPOTHESES: (1) Learners might pronounce common phonemes between Chinese and English better than the exclusive phonemes of Chinese (EPC).

(2) Learners might confuse EPC with similar phonemes in English, if similarities exist.

The most challenging phonemes and syllables in Pinyin Table are discovered as follows: The most challenging initial consonants are: $/ \mathrm{x} / / \mathbf{q} / / \mathrm{j} / / \mathrm{w} /$; The most challenging simple vowels are: /u:/ /e/ /u/; The most challenging multi-vowels: /ui/ /iu/ /ie/ /un/; The most challenging whole syllables: /yu//ye/. These conclusions are made through descriptive statistical analysis for the data generated from a Pinyin Table Reading Test with 19 participants.

Among the four tones: tone 3 is the most challenging; tone 1 is the easiest; and tone $2,3,4$ are very likely to be mispronounced as tone 1 . These conclusions are made through descriptive statistical analysis of the data generated from the Text Reading Test with 19 participants. 
Pronunciation in the Text Reading Test, and especially with the accuracy of pronouncing Tone 3, which is the most melodic. However, when rating their own musical ability, participants' attention shifted to the melodiousness of their own sound, hence, the results from the Self-Rating Scale for Musical Ability were found to correlate with the accuracy of reading the initial consonant.

Table 3: Themes, sub-themes and categories

\begin{tabular}{|c|c|c|}
\hline \multicolumn{3}{|c|}{ THEME 1: CHALLENGES LEARNING AND TEACHING CHINESE PHONETICS } \\
\hline \multirow{3}{*}{$\begin{array}{l}\text { Sub-theme } 1.1 \\
\text { The difficulties the teacher } \\
\text { experiences teaching Chinese } \\
\text { phonetics }\end{array}$} & \multicolumn{2}{|c|}{ Chinese language complexities and resultant classroom management } \\
\hline & \multicolumn{2}{|c|}{ Huge differences between English and Mandarin } \\
\hline & \multicolumn{2}{|c|}{ English language transfer } \\
\hline $\begin{array}{l}\text { Sub-theme } 1.2 \\
\text { What learners find most difficult } \\
\text { about learning Chinese phonetics }\end{array}$ & \multicolumn{2}{|c|}{ Tones, characters, Pinyin, sentence structure } \\
\hline \multicolumn{3}{|c|}{ THEME 2: ASPECTS TO CONSIDER WHEN LEARNING CHINESE PHONETICS } \\
\hline \multirow{4}{*}{\multicolumn{2}{|c|}{$\begin{array}{l}\text { Sub-theme } 2.1 \\
\text { The teacher, research school and learners }\end{array}$}} & The teacher's teaching method \\
\hline & & The school in a South African context \\
\hline & & Ways that learners learn characters, tones and Pinyin \\
\hline & & What learners enjoy most about learning Chinese phonetics \\
\hline
\end{tabular}

Regarding this study, a narrative style was used to discuss the quantitative conclusions and, in so doing, allowing the qualitative part of the mixed method to take the leading role in a discussion of the findings. The qualitative data (harvested from individual learner interviews, the individual teacher interview, observations and the literature) enabled the researchers to use thematic analysis to arrive at the themes, which offered structure for also integrating/complementing and arranging the quantitative conclusions under the appropriate theme/sub-theme. The sub-themes and categories are naturally incorporated under each theme.

\section{THEME 1: Challenges of teaching and learning Chinese phonetics}

\section{SUB-THEME 1.1 The difficulties the teacher experiences in teaching Chinese phonetics}

Tř́sková (2017: 3) explains that "[p]ronunciation is one of the essential aspects of the acquisition of Chinese as a second language". It is also difficult because of the tonal character of Chinese and, of course, the Chinese script is "enormously difficult" and complex. The teacher participant $(\mathrm{T})$ in this study explained:

I think because [...] of the characters ... but if you look at the characters from another angle, you see it's kind of like drawing a picture. Some people they like that, because it is a kind of a form of art, but some people they refuse it. Most of them struggle with characters writing and then they ask me why there is a certain stroke order they have to follow - we start[ ] from the numbers - the least strokes [...]. I explain [to] them it is the best way for them to learn how to draw, but once they are familiar with it, of course they don't have to draw it precisely. The most [challenging] is this one. Second [...] is the sentence arrangement, because it is the opposite way of the English-we put the time word in front of the sentence, but in English the time is always put at the back.

The teacher admitted to feeling overwhelmed: "Recently I just struggle with classroom management - with a certain class, their behaviour is disturbing - I ask help from the busy principal". As L5 explained, "our class is very very very noisy". LR added: "In the earlier grades, I used to struggle very much with Chinese and when I'm in a room with other classmates, I usually can't concentrate well because of the noise in the room." 
It is almost impossible to "avoid a particular difficult consonant, vowel, diphthong or tone, or skip word stress, sentence intonation, etc." (Tř́sková, 2017: 4). T pointed out that some of them are confused - they ask me why they are different characters, and even in the test paper they always [find it] easy to make mistakes. English sounds precisely Chinese sounds the same, but [the] meaning differ[s]. I find all learners so talented in learning language, like I think most of the African learners are very talented in language and also English-speaking learners. Some Chinese phonemes are more difficult, like the $T Z$ - yes that's right - not easy for them to remember it, like I may say they must write it down, they must spell it, but they can pronounce it easily, but writing is more difficult.

As LC stated: "There might be some sounds that are the same, but the difference that the sounds weren't. If you take a specific word [...], it won't match. It won't be the same sounds exactly to the English."

L3 explained: "In English it's Q. But in Chinese, that Q, if it's got a different tone, makes it more difficult."

The teacher felt that for English learners, memorising Chinese characters was not really problematic:

I don't think so - it does not matter, it's all the same - we do have Portuguese, from Russia [...], from Romania - no different. They [are] already multi-[lingual] at homeit might be [...] because [of that]. I do believe each language ha[s its] certain way, certain grammar like Spanish they also arrange differently, sometimes they may apply the Spanish grammar in English all the time.

L3 added: “... there are many differences [...] In English you don't have characters that you have to write. The Chinese you have [a] tone sign that you have to write on the words."

LR admitted: "It was easier for me to learn Afrikaans than [...] Chinese, because [...] Chinese is more difficult [...]. It's a much different way compared to the English and Afrikaans, there [are] no characters. Because there [are] two ways in writing with Pinyin and characters. So I said the Chinese is completely different and much more difficult than English."

In addition to the reading, writing, listening and speaking challenges of learning Mandarin, the cultural aspect plays a vital role, as there is a "marked social distance" between native English speakers and native Mandarin speakers (De Man, 2017:36). However, T mentioned that "like pizza, we use it directly the same [...] some[times] we use [the] same words ... The characters are different but they sound the same - like Man-de-la". In this study the researchers hypothesised that the factors which are most likely to influence learning Mandarin are phonemic differences between English and Mandarin (phonemic pronunciation); learners' learning styles (tone pronunciation [see VARK) and learners' singing and tone imitation (tone pronunciation).

As T explained:

Chinglish - so it's like the Chinese grammar English - they always have this kind of habit, because I'm always Chinglish - English learning to Chinese - they just transfer English directly into Chinese, that's the way - do direct translation first and they can rearrange.

L3 explained: "I can't think something in English so that I can learn it easier in Mandarin ... I try [to] translate it into English and speak the same way.". LR stated: "So the 'ie' sounds like ' $a$ '. LC said: "The sound and the words don't have anything to do with English ... so it's very different." 
Lai (2009: 1267) suggests that a phonological comparison be made between the native and target languages. Huang and Evanini (2016: 272) suggest that providing English L2 pronunciation patterns will allow one to better understand the transfer effect, when learning the L2 pronunciation. Motor coordination between the mental representation of the sounds and the articulatory organs is involved in phonological production, thus pronunciation errors may be attributed to "perceptual confusion, motor execution or automaticisation" (Huang \& Evanini, 2016: 272). McBride (2015: 523) adds that learners' basic visual skills can also be strengthened, along with their cognitive development, to enhance the learning of Chinese characters.

\section{SUB-THEME 1.2 What learners find most difficult about learning Chinese phonetics}

Learners who were able to imitate the nonsense melody and tone imitation, that is their pitch of the note, also proved to have an advantage in being able to read the reading text and, in particular, to pronounce the third tone (the most melodious), despite finding it the most challenging tone. Since tone 1 seemed the easiest to pronounce, learners had difficulty discriminating between tones 2, 3 and 4, and were inclined to mispronounce them due to their familiarity with tone 1 .

\section{Tones}

$\mathrm{Hu}$ (2010: 104-105) explains that Pinyin is used to help a learner pronounce characters and 21 consonants, 36 vowels/semi-vowels which are combined into Chinese syllables, the latter being marked by one of the four tones/neutral tone. These tones play a major role in distinguishing the meaning of a word, e.g., if "wen" is pronounced with a rising tone, it means "to smell", but if pronounced with a falling tone, it means "to ask". The position of the tongue must be accurate, and changing the pitch of one's voice when sounding out the isolated and clustered tonal syllables, is challenging.

T explained: "I think sometimes they struggle[e] with the $3^{\text {rd }}$ tone because in English its [a] very light sound. [It is easy] to make mistakes - let me think about - uh - the syllable? I think its $\underline{\text { chi }}$ and $\underline{\text { sh }}$, also shi - this one's about the tone - they mix up.

LC commented" "... the tone signs [are] very specific. And if you say something [...] with a different tone sign, it should mean something [else]. LKK added: "A Chinese person might not be able to understand you." . LJ observed that the "second and third, not the first, [...] they sound the same to me. As LI stated: "I found really difficult the 'qu'. Usually, if you write 'qu'[...] with this tone symbol, it is like 'shoe', but it's not 'shoe' and it becomes confusing, so I have to practise it a lot."

It can be concluded from the participants' responses that many learners found the third tone the most difficult to pronounce, the reason being that it sounds similar to the other tones. Some found the fourth tone challenging as it needs to be pronounced precisely, and yet others found the second tone to be more difficult.

\section{Characters}

The learners expressed that most of the characters look the same or have too many strokes to remember, which is confusing. It thus requires a great deal of practise, as LSS said: "... if it's like one character, but it has two characters beside it, [it] is difficult ... because a lot of the characters looks like a mouth for instance ... you have to practise the characters [...] a lot." As LTT said: "It's got to be very neat [but] if I recognise the character, then I can piece 
together the sentence again." LR responded: “... because [in] the old days they use [d] big characters, but now sometimes they are small, very small, easy characters."

LDD stated:

With the characters you have to memorise different symbols. Well, I just find normally when you can draw characters, but sometimes I find there's a lot for specific characters, some characters are easy, but specific ones are very hard, and there are lots of strokes. And then I find it hard to memorise how each stroke goes, and where lines are supposed to be.

The majority of the learners noted that the simpler the character, the easier obviously, but the more complex and the more steps in the character, the more difficult it is, as the sequencing and the numbering become more complex, requiring a great deal of memorisation. As LKK mentioned: "And then you must know, you must know that number, that number two, that number three. That... this one goes this way, that one goes up, the other one goes down." LDD added: "But then sometimes [...] when there's a lot of dots, it's a kind of frustrating, because you have to do the dots over and over. Because perhaps even if you've got the dots that can guide you, you still have to know whether you must go up or down or backwards or forwards or whatever." LKa admitted struggling with "[p]ronouncing the Pinyin on the character. The tone, because some of them have exactly the same spelling, but different tone signs."

In Shen's (2005: 61-63) study it was found that "orthographic-knowledge-based strategies" were mostly used by first-year university students who had little/no knowledge of Chinese, mainly because of the Chinese script's graphic nature. These strategies included cues such as radical knowledge, graphemics, semantics and phonetics to encode a character. Non-native learners used radical knowledge to learn a character and look for "sound-shape-meaning connections" in the character, but because they had limited orthographic knowledge, they found it difficult to learn characters. Thus, it is imperative that beginners be introduced to radical knowledge as soon as possible, as it will facilitate character learning.

\section{Pinyin}

Lü (2017) describes Pinyin as "a sound-annotating system for Chinese characters using Roman letters", noting that when taught to second-grade learners in an immersion Chinese programme, for instance, it "facilitates subsequent Chinese word reading".

When participants were asked whether Pinyin was much different to English, their responses were varied. LDD explained that

... most different from English. [...] you can see the differen[ce]. Remember, you write it like you write English. I think it's much [...] different, because I even need to struggle because in Pinyin you have all of these tone signs. You write on top of the word too, and different signs that you get different times on top of the word and seems like the word can [be] different, even [...] the same word with different signs can. So, I actually used to struggle with the tone sense, because it's hard to memorise. I actually prefer when you first learn Pinyin, I find it very easy to learn Pinyin because it's like words, even though there are some difficult tones and I just find it easier.

What is evident is that although the words are Romanised, LDD stated: "That's so, they look the same, but they don't sound the same because the second tone goes up and the fourth tone goes down and quick. So it doesn't ... it doesn't really sound the way you see it. Yes, it doesn't." 
Examples are the $\mathrm{q}, \mathrm{i}$ and $\mathrm{x}$.

\section{Sentence structure}

$\mathrm{T}$ explained that a challenge "is the sentence arrangement, because it is the opposite way of the English - we put the time word in front of the sentence, but in English the time is always put at the back". LSS responded: "In Mandarin you see, 'I don't kick ball', but in English you say 'I don't like kicking the ball', is like, is the sentence structure". L9 said: "Sentence structure, it's kind of mixed, because let's say you would put a word at the beginning in English. In Chinese, probably at the end or in the middle."

It is important to distinguish between the correct use of a class of words regarding syntax and "using the items in that class correctly and appropriately" (Hu, 2010: 102). Some Chinese grammatical structures do not have English counterparts; in Chinese only grammatical (meaning they express the relationships between concepts)/connotational are used; the Chinese word order may be very inflexible, as syntactic groups in a sentence are placed according to strict rules. For example, an adverb precedes a verb which is then followed by complements and noun modifiers, and relative clauses are to be placed before a noun. This syntax inflexibility makes it a challenge for the learners to make a grammatically correct sentence (Hu, 2010: 102103).

L5 explained: "Okay, well, there are some that sound like really, really different from each other. Like, let's say to get out of bed is 'Qichuang', I would have never guessed getting out of bed is that because it's like five words [in English], and in Chinese [it] is two. So it didn't sound the way it looks." LKK said: "... and depending on [...] the sentence structure, $[\ldots]$ the way we see the words."

L5 remarked: "Well, sometimes if I can't get to the English words quick[ly] enough, and I sometimes use Chinese because it's [...] not the proper sentence structure. Like if I don't, if I want to say 'hurry up' and I can't think of it then I'll just say 'Kuaidian', because that's like 'quickly', so but then afterwards then I remember, oh yes, hurry up."

L7 said: "But otherwise a lot of the English sentences are the same as in Mandarin, for instance. 'I wake up in the morning', [is] also those same words. Yeah in the sentence. And the same uh, order sequence. yeah, sequence. But like some of them are different."

\section{THEME 2: Aspects to consider when learning Chinese phonetics}

The teacher, research school and learners

The participant teacher (T) comes from Taiwan and her mother tongue is Mandarin, as her parents speak Mandarin Chinese. She learnt to speak English in school in Taiwan. In 2012 she started to teach Mandarin in South Africa, using the Taiwan Embassy Programme, and has been teaching Mandarin on and off for about six years. She learnt to teach Mandarin in South Africa, since she obtained a Postgraduate Certificate in Education (PGCE) at the University of Pretoria in 2016, explaining: "My Mandarin is good - [I know this] mostly from learners' feedback - their reaction to me." She was formally appointed at the school at the beginning of 2018. She explained: "At the beginning I sent my children to this school-I was teaching in the Saturday class - the Chinese class. I am teaching the native-speaking, so it is not eas[y] for me. I grew up [in] Taiwan, so we have all the teaching resources from our embassy - we use the Taiwanese materials." As LKK explained: “... in English, there [are] more teachers, but in Mandarin this one. One teacher [who] teaches us everything." 
The school in a South African context

The participating school caters for learners from Grade $\mathrm{R}$ - Grade 12, and follows the South African CAPS curriculum. The LoLT is English, however for native Chinese learners it is Mandarin. Seeing that it is a Chinese school, non-native learners (e.g., Portuguese, Romanian, Afrikaans, South Korean, various African languages) receive 30 minutes of Mandarin classes a day. On advice from the teacher, we chose the Grade 6 learners, seeing that most of them have been exposed to Mandarin since pre-school, and are reasonably familiar with the language. The teacher has a weekly plan:

I plan monthly and weekly, not daily. Actually we follow the school's schedule. We have the CAPS to follow - only Grade 4 up. We do not have pressure - CAPS they make too hard, but the intermediate too easy. We follow CAPS now the teaching is more... We [are] teaching a lot of advanced level. Our contents [has] so many varieties, they must follow CAPS - more than what they should learn. We give them more extended work, that's right. For every teacher it's too hard in CAPS.

According to the teacher, every two weeks they have class tests and every two months cycle tests (i.e., revision of the term) and prepare the learners to write the exams. In the next test she asks them the same questions again.

Other factors which play a role in learning Chinese phonetics are the Pinyin Chinese phonetic system, local schools' contexts, and the CAPS curriculum (as discussed).

\section{Teacher's teaching method}

The teacher explained that her teaching was more learner-centred, which was part of her PGCE training. During training they had to apply learning materials, cater for different learning styles and facilitate learners' learning.

When asked whether learners learn to read different orthographies in different ways, $\mathrm{T}$ responded:

$J a$, they learn Pinyin differently to English - like the letter $C$ line in CAT but in Pinyin

$C$ is TZ. There is a big difference: teaching the C Pinyin, I let them know it sounds [like] 'TZ' - sometimes we use pictures of vegetables, use an audio clip. Some are visual learners, some are kinesthetic - for that we use games, repeat sounds, list the cards of each phonic[ ], consonants and vowels ... like bingo. Yes, they like the audio and video things - those [who are] visual - their natural response. Our textbook is [linked] to our CDs that they can do.

$\mathrm{T}$ further explained:

They need the phonics because it's part of the listening skill. We start [with] listening, but we say in language learning it's four processes: listening, speaking, reading and writing. So we all start from listening, so it is important to listen first. Yes, English code switch to Mandarin - [that is the] best way to teach. Ja, for beginners they need to put lots of information in the word bank - eventually [we] withdraw and then teach purely in Mandarin.

The participant learners' responses, on how the teacher teaches, included the following:

She uses a textbook which she teaches from - she uses the same topic for the activities when teaching Mandarin; she teaches writing characters step by step (as it makes it easier) within the context of a sentence and emphasises meaning; T uses mnemonics, for instance, "this is the mouth of the character", and L DD added "The character she actually shows us ... like it 
actually looks like a little man". Characters are practised by writing then over and over, and also following the dots to complete the character; in tests the teacher writes the Pinyin and the learners write the corresponding characters; assignments are sometimes done in groups; she may say a word in Chinese and learners need to translate it, and she also reads to them so that they can hear the pronunciation. In this regard, L9 said: "They taught us and helped us through everything. If you don't understand, you'd ask the teacher or something."

From the correlational analysis, it appears that having a preferential aural learning style is a good predictor for learn to read Pinyin and tones. The teacher explained that English learners "learn the same - its only [...] personal styles of learning. I don't think that will be a barrier." The teacher added that Pinyin has "a major role, yes, because we don't have any clue to see how to sound the characters - no clue, here only [...] the Pinyin help[s] them."

To the question whether strong visual skill are an indication of being able to learn to read Chinese characters, the teacher responded: "Yes of course. We use a lot ... its visual things, but of course you must put in some imagination because I explain to them [that] Chinese is fun, like Lego. Just put parts here and form another character - two people sitting on a bench is how I help them to memorise characters."

As regards listening, T stated: “... I read first and they must repeat after me, my pronunciation - they must listen to me - our teaching material is from level 1,2,3 .. we using these level[s]. We have projects, work in groups and learners work collaboratively." About speaking, T commented how important it is "to pronounce properly"; about reading, the importance of "recognis[ing] the characters and the Pinyin together" and about writing, "stroke order"; and about intercultural understanding: "respect each other. Actually, I don't see difference among them - [learners are] universal."

\section{Ways that learners learn}

While learning styles do affect "strategy use in learning", "linguistic features of the Chinese language impacting on learners' cognitive processing play a vital part in the use of character learning strategies" (Shen, 2005: 63).

\section{Characters, tones and Pinyin}

When asked how the learners learn Chinese phonetics, L6 answered: "So usually, like I find a way to connect the word and the tone sign, and then in that way I remember how to say them ... So it's easier to remember the tone sign then the sign... over again...".

Generally, learners responded that they learnt characters by remembering the stroke order, and by repeatedly writing the character. Interestingly, the learners have different ways of learning the language. As LI said: "Usually when I get home with my ... revision cards and I write the character the right Pinyin, then I write the meaning and then I like, write the pronunciation in English ... sometimes I make mistakes on purpose. So remember that mistake, and then I remember. ." LDD commented: "So I give myself the Pinyin, then I cover the character and write down the character. then I reverse to write down the Pinyin, then I shuffle up the words and write it again." L9 explained: "I guess just writing sentences helps me more. [...] sometimes my mom ... Walking in circles can actually help [me] concentrate, so I read them out loud first and then when it comes to characters, I write them down continuously."

When learners were asked about the easiest way of learning the sounds and meaning, LR said: "I usually ask Laoshi (teacher) to first say to [me], I see if I can pronounce it just as well as 
Laoshi. But I ask to say to me. We have to, in Chinese, we can speak English and read the speech we have to say in Pinyin."

Although the learners deemed themselves as having good singing and tone imitation abilities, they were only able to pronounce initial Pinyin consonants (except $x, q, j$ and $w$ ) depending on their own melodic sound frame of reference. The same cannot be said about the rest of the Pinyin table. Can it be that learners have a false sense of their singing and tone imitation abilities? Since there is a great divide between Pinyin and English phonemes, and given that the learners were not acquainted with the Pinyin table (albeit knowing some of the sounds), they might lack self-confidence and boldness, and that can contribute to their inability to pronounce the rest of the Pinyin phonics table. They may also have depended on transferring what they learned in their mother tongue, to Pinyin. It may be negatively transferred to the phonetic level, where their foreign accent may influence the pronunciation of the Pinyin phonemes (Wang \& Xiang, 2016: 2208-2210).

LC said: “... if you are able to speak and pronounce Mandarin words, it's very different. Because the character doesn't look or sound ... not sound, it isn't look like the Pinyin... because [...] if you just look at a character and a Pinyin word that you, for example, [have] never seen before, then you wouldn't know if it's the same thing." L7 explained: “... 'meimei' is 'sister'. In English, [it] is sister. It [is] just sister. One word but in Chinese [it] is two words."

LSS stated: "I usually break up the word in trying to understand it. And then sometimes I go home and write it on my white board, [...] like ten times, into this in my mind."

LDD added: "....sometimes we test each other on Chinese, to make sure we understand that when we speak."

LKK opined: "The CDs says something in Mandarin, and then we have to understand that you have to write A or B. I write down the characters, then I write down the Chinese [...] word on the Pinyin. Yeah, write on the Pinyin under the character, and then write the English next to the Pinyin. No, what I do first is look at the character, then I write down the Pinyin and then I learn the English."

\section{What learners enjoy the most learning Chinese phonetics}

Amongst the learners' responses, there was an overall positive view of how the Chinese phonetics are taught. The conclusion is that the teacher was flexible in her teaching (taking into account that she acquired learner-centred skills during her PGCE training). The teacher allowed the learners to find ways to develop various learning skills which worked for them, and made provision for their enjoyment of the lessons, which in itself was a motivational strategy. LT confirmed this: "I'll have to repeat [it] until I get it correct. I like to learn it like that [...]. So that is the best way, for all my subjects are learned with the pictures." Khajavy, MacIntyre and Barabadi (2018: 605) found that willingness to communicate is fostered by a positive classroom environment, as well as enjoyment. Enjoyment plays an important role in increasing willingness to communicate on a learner and classroom level. When teaching and learning a second language, storytelling has many benefits, such as improving learners' language skills (e.g., recognising the language structure), better comprehension and classroom interaction (Nguyen, Stanley \& Stanley, 2014: 29, 38).

$\mathrm{Hu}$ (2010: 111) points out that it is important that learners' learning styles be considered when teaching them. "Grammar is the most heavily-loaded factor and thus can be said to represent 
an area of perceived difficulty for CFL learners, regardless of their levels and or their learning styles" (Hu 2010: 109). The learning styles and activities/ways of learning are expressed by the following participant learners:

LI: "I enjoy listening to the teacher, because [she] usually teach[es me] things I like. I like writing... Writing is the best activity in learning Mandarin. I mostly love writing, but English I must read. So It's easy to write, I think that's the easiest."

LR added: "The multiple choice [activities]... the choices to know which one is right."

"I like mostly Pinyin because [it is] easy to read. But if there [are] characters, I will still do the characters."

“... we do learn interesting words. We usually say [them] to each other, and juniors listen to [us], but do not know what's going on. So, it's a good feeling? Wow, they [family] keep telling me that they still can't believe 'you're learning Mandarin', because they think it's still so difficult. When I get good marks in my tests, they [are] very proud of me, because they keep telling me they wouldn't be able to do that."

LTT mentioned: "I like tracing down the characters using cut and color, coding them for which strokes."

LDD said: "... she also sometimes makes us learn songs, and then she tells us we [should] choose a song and a partner, then we come in front of the class and start singing. I enjoy that."

LKa said: "I prefer doing Pinyin.It is easier because the characters are like lots of lines. And that Pinyin has $[\ldots]$ only one."

LC admitted enjoying learning the characters: "I love the way that the characters are. They [are] just so different and unusual and it's very arty."

Many learners said they enjoyed listening to CDs; listening and speaking to the teacher and asking the class to repeat; reading to their classmates (in pairs or the whole class) or reading together as a class (e.g. a dialogue); writing the characters repeatedly; the use of pictures; listening to stories; using colour coding for the characters on worksheets; doing assignments in groups or pairs; role playing; and speaking to each other and laughing.

\section{Discussion, conclusions and recommendations}

In South Africa, Mandarin Chinese was added to the list of SALs (from the Intermediate phase, [grades 4-6] to the Further Education and Training phase [grades 10-12]) as an elective (DBE 2015: 4-5). However, De Man (2017) cautions South Africans to take care how the English generic curriculum was used to study Mandarin Chinese. Notably, one cannot apply alphabetic literacy development models to Chinese literacy development and just tweak them. There are aspects of Chinese literacy acquisition which are fundamental as well as unique (McBride, 2016: 545). In the case of Chinese literacy development, certain aspects "do not conform to patterns of literacy development in alphabetic orthographies" (McBride, 2016: 523). Hence, the authors of this article were compelled to focus on phonetics and the factors impacting on acquiring them, ultimately arriving at this research question: Do factors such as 1) phonemic differences between learners' mother tongue and Chinese, 2) learners' cognitive styles and 3) learners' abilities of singing and tone imitation, influence non-native learners of Mandarin (as a SAL) in South Africa to learn Chinese phonetics? 
To answer the RQ adequately, we deemed it necessary to make use of a mixed-methods research design. The quantitative part included determining learners' learning preferences; musical ability; ability to imitate tones; ability to read Pinyin phonics and text reading ability. The qualitative part included interviews with learners and the teacher regarding the teaching and learning of Chinese phonics. In so doing we were able to integrate and complement the quanqual data and arrive at conclusions which could contribute to the existing body of knowledge.

The factors which had an impact on the participant learners' acquisition of Chinese phonetics emerged during the quantitative part of the research. The conclusions were used as a point of departure for the qualitative part of the mixed method (the main source of data in this article). The findings revealed that there was no significant correlation between learners' learning styles and their acquisition of Chinese phonetics; that learners' self-rating of their musical ability enabled them to read initial consonants accurately (albeit that this was not the case with simple and multi-vowels, whole syllables and tone pronunciations). Where learners imitated the melody accurately, it correlated with their accurate tone pronunciation in the reading test, especially tone three. The authors are convinced that where learners have a realistic opinion of their musical ability, they are apt to read the Pinyin phonetics table better. Good performance in the singing test correlated well with the tone pronunciation in the reading test, particularly tone three which is more melodic. Learners found the initial consonants, namely $/ \mathrm{x} / \mathrm{qq} / \mathrm{j} / / \mathrm{w} /$; the vowels /x//q//j//w/; the multi-vowels /ui/ /iu//ie/ /un/ and the whole syllables /yu/ /ye/ on the Pinyin phonics table most challenging to pronounce. Since tone 1 appeared to be the easiest to pronounce, tones 2, 3 and 4 were often pronounced as tone 1 .

Perfetti et al. (2013: 9) explain that "when a character is read, phonology is activated ... phonology is part of reading characters in Chinese, just as it is part of reading words in English". However, the implementation of phonology in the two systems is very different. "Phonology is a universal component of reading but the procedures that bring it about depend on the linguistic units provided by the writing system" (Perfetti et al., 2013: 9). Tan et al. (2005: 8781) point out that the logographic characters are based more on meaning than phonology. Thus, being able to read Chinese is related to one's writing skills, hence orthographic awareness helps to develop "coherent, effective links among visual symbols, phonology and semantics". Motor programmes on the other hand help to form long-term motor memories needed for Chinese characters. In fact, Suk-Han Ho and Bryant (1997: 946) found that "prereading phonological skills" are a predictor of learners' Chinese reading later on. Phonological knowledge helps a child "to use the phonetic component in Chinese characters".

Difficulties which the teacher experienced in teaching Chinese phonetics were mainly due to the complexity of the characters, such as the stroke order - especially where there are multistrokes. This makes a great demand on the learners' memory, precision and repeated practise which are time consuming. The difference in sentence structure and sounds (some look the same but sound different) compared to English sentences and sounds (and of course the tone signs) is a great source of difficulty. Although orthographic knowledge is an advantage, this is often limited or non-existent in non-native learners. Some learners recognised the advantage of learning Pinyin, while others found it difficult, seeing that it requires one to be able to discern the tone signs, and to know when and where they are used. English interference/L1 transference, where the learners translate directly from English to Chinese, is also problematic as learners find there is a great divide between the languages. Learners also encounter difficulties with the four tones, because if one does not use the tones appropriately, the meaning is lost: for example, some learners find the second and third tones difficult to discern, as they sound similar. The teacher explained that the learners make many mistakes where the third tone is involved. 
According to the teacher and learners, these difficulties lead to learners becoming demotivated, and they resort to rowdiness which makes classroom management difficult.

The participating teacher in this study had adopted a learner-centered approach, was cognisant of learners' learning styles and catered for each (i.e., visual, auditory, kinaesthetic). Moving away from the rigidity of rote learning and allowing greater flexibility and learner agency allowed the learners to find their own ways and means, in addition to the teacher's ways, to acquire the language skills. The participating learners attested to this approach by expressing their learning enjoyment, inter alia, learning with the use of pictures and listening to CDs; story telling; multiple-choice questions; group work/in pairs; the use of tracing, cutting, colouring and coding characters; singing songs; reading activities; dialogue and role play. Khajavy et al. (2018: 605, 620) found that where there is a positive classroom environment which includes the 'teachers' support, students' cohesiveness, and task orientation", willingness to communicate (WTC) is fostered, as anxiety is reduced and learners enjoy the lessons.

Teachers who teach Mandarin at the research school find it extremely difficult to follow the CAPS curriculum, as the content is so varied. There is a desire to present a well-thought-through Mandarin curriculum and pedagogy, and this would require input from Mandarin language experts. Digital games are beneficial to use in support of the curriculum, but teachers use games which are "short-form drill-and-practice learning games", as opposed to the games learners play during their leisure time. The use of more interactive and immersive digital games depends much on the ingenuity and enthusiasm of the teacher. Many teachers do not know how to use digital games in the classroom. Games are significant in a learner's life and can be used as tools to improve learner outcomes across subjects (Stieler-Hunt \& Jones, 2019: 264-265).

Halliday (2014: 5) suggests that it is essential for a Chinese teacher who is teaching Chinese to foreigners to know the phonemic script of the language very well, that is, to read and write Pinyin fluently and accurately. Halliday (2014: 1) found that to teach foreign learners Chinese, it is best to be taught by teachers who speak the same language as the learners, to introduce Chinese characters only at a later stage, and to aim to achieve phonological accuracy in Chinese. De Man (2017: 108, 115) advises that taking the local context into consideration, where most schools were deprived of opportunities and are presently on the road to recovery (particularly regarding the shortage of knowledgeable teachers [varied backgrounds, experience and training levels]), they need a detailed programme (plan of work) to teach Mandarin as a SAL. Yang, Fox and Jacewicz (2015: 1125, 1141-1142) found that a monolingual Mandarin boy initially used his L1 vowel base to build the L2 vowel system (English). He first separated the L1-L2 by means of "restructuring his working vowel space" in order to contrast the two languages. By doing this, he was able to expand the L2 vowel space as he discovered the L2 phonological contrasts and subsequently the two vowel systems were separated.

Halliday (2014: 2) reports that whilst learning Chinese, he devised his own strategies - for example, to memorise a new character he would use the blackboard and would "write with the full extension and movement of the arm", singing a tune which matched the rhythm of the strokes. He would also arrange the characters into groups according to their phonetic element, putting them on playing cards with the character on the one side and the English on the other, and playing a game. During the course the students also had coursebooks, newspaper articles, essays and short stories in Chinese text available. Halliday (2014: 4) found that there are four scales of variation in which learners learn:

1. By ear (listening and speaking) or eye (reading and writing)

2. By performing (doing) or reflecting (thinking, planning) before they perform 
3. By content (the meaning) or expression (focusing on sound and sight), and

4. By principle (top-down generalisations) or by examples (bottom up, finding a pattern by him/herself).

Learners who are willing to communicate in a foreign language demonstrate a variety of individual differences which allow them to find and take advantage of opportunities to practise L2. Where statistics are concerned, keep in mind that learners share factors such as their classroom environment; relevant common experiences; the same teacher and they perform the same activities at the same time; they share the same classroom atmosphere; the classroom is in a school which has physical attributes and operates within a socioeconomic and political context; the school leadership and state-level curriculum planning have an effect, etc. Thus, learners cannot be treated independently where these factors are present (Khajavy et al., 2018: 606-607).

Orton (2016: 374) recommends that more research be conducted regarding the nature of learning tasks for English learners; more dialogue is needed between those in China who educate teachers outside China (language and resources). It is important for Chinese teachers to understand the educational culture of foreign societies, and to appreciate the use of Chinese in an international context. This requires a great deal of collaboration and communication. For the teaching of Chinese in the future, the recommendation is to include lessons three times a week or more; find new ways of presenting Chinese; and teaching other subjects, such as Science, in Chinese, using the immersion approach (Orton, 2016: 374).

De Man (2017: 147-158) recommends that a language-specific curriculum be developed; despite the provision of SAL in the Senior Phase (grades 7-9), no provision has been made for Mandarin in the Intermediate and Senior phases, thus an entry level in grade 8 is necessary. This means there is no continuity in the high school or transition from primary to high school; the importance of managing a mixture of learners in one class (e.g. L1 learners, learners who come from a Chinese background and SL learners); changes are needed with respect to the proficiency level of listening, speaking, reading and writing, as presented in the CAPS Mandarin SAL, as well as approaches such as the text-based approach in the Intermediate phase needs to be adjusted using "structured and scaffolded situations" (De Man, 2017: 156); a clear Pinyin-character policy is needed; and the teaching of culture and cultural aspects needs to be incorporated in the CAPS Mandarin SAL.

\section{Acknowledgements}

1. To Pan Lu Qiu Chang, who at the time of the research was affiliated to the School of Educational Science, Zhejiang International Studies University (ZISU), Hangzhou, China, we express our gratitude for

- presenting his proposed research during our visit to ZISU in 2017, and subsequently inviting us as co-researchers in his study.

- preparing a detailed proposal and availing some data-collection tools for us to use during the research.

- availing his statistical data analysis for us to use in our article writing.

Please note that Pan Lu, Qiu Chang has made a career change and has since withdrawn from the project, ceding co-researchers the right to use all of the above.

2. We thank Angela Liu, Deputy Principal (Chinese) at the research school for her input in the manuscript relating to examples of characters and their meanings. Our sincere thanks to the learners and the teacher of this same school, who participated in the study. 


\section{References}

Braun, V. \& Clarke, V. (2006). Using thematic analysis in psychology. Qualitative Research in Psychology 3: 77-101. https://doi.org/10.1191/1478088706qp063oa

De Man, M. (2017). The Mandarin Chinese second additional language curriculum for South African schools: considerations and possibilities. Masters dissertation, Stellenbosch University. https://scholar.sun.ac.za

Department of Basic Education (DBE). (2014). Curriculum and Assessment Policy Statement Grades 4-6: Mandarin Second Additional Language. [Online]. http://www.education.gov.za/Curriculum/NCSGradesR12/CAPS/tabid/420/Default.as px

Department of Basic Education (DBE). (2015). Republic of South Africa. Regulation Gazette No. 10396. Government Gazette 597(38589), 1-8.

Dörnyei, Z, (2007). Research methods in applied linguistics. Oxford: Oxford University Press. ISBN: 978 o 194422581

El-dali, H.M. (2019). An alternative approach to linguistic theories of language acquisition: focus on the cognitive theory. Journal of Advances in Linguistics 10. ISSN: 2348-3024. https://cirworld.com/index.php/jal

Gitsaki, C. (2018). Second language acquisition theories: overview and evaluation. https://www.researchgate.net/publication/37617738

Halliday, M.A.K. (2014). Notes on teaching Chinese to foreign learners. Journal of World Languages 1(1): 1-6.

$\mathrm{Hu}, \mathrm{B}$. (2010). The challenges of Chinese: a preliminary study of UK learners' perceptions of difficulty. Language Learning Journal 38(1): 99-118. Doi: $10.1080 / 09571731003620721$

Huang, B. \& Evanini, K. (2016). Think, sink, and beyond: phonetic variants and factors contributing to English th pronunciation among Chinese speakers. Journal of Second Language Pronunciation 2(2): 253-275.

Khajavy, G.H., MacIntyre, P.D. \& Barabadi, E. (2018). Role of the emotions and classroom environment in willingness to communicate: applying doubly latent multilevel analysis in second language acquisition research. Studies in Second Language Acquisition 40: 605-624. Doi: 10.1017/S027263117000304.

Lai, Y. (2009). Asymmetry in Mandarin affricate perception by learners of Mandarin Chinese.
Language and Cognitive
Processes 24
(7/8):
1265-1285. Doi: 10.1080/01690960802113850

Li, M. (2019). An application study on the phonics in English vocabulary teaching for Chinese primary schools. $9^{\text {th }}$ International Conference on Education and Social Science (ICESS 2019). UK: Francis Academic Press. Doi: 10.25236/icess.2019.022

Li, T. \& McBride-Chang, C.C. (2013). How character reading can be different from word reading in Chinese and why it matters for Chinese reading development. In: Chen, X., Wang, Q. and

Lü, C. (2017). The roles of Pinyin skill in English-Chinese biliteracy learning: evidence from Chinese immersion learners. Foreign Language Annals 50(2): 306-322. https://0doi.oasis.unisa.ac.za/10.1111/flan.12269

McBride, C.A. (2016). Is Chinese special? Four aspects of Chinese literacy acquisition that might distinguish learning Chinese from learning alphabetic orthographies. Educ Psychol Ref 28: 523-549.

Nguyen, K., Stanley, N. \& Stanley, L. (2014). Storytelling in teaching Chinese as a second/foreign language. Linguistics and Literature Studies 2(1): 29-38. 
Orton, J. (2016). Issues in Chinese language teaching in Australian schools. Chinese Education \& Society 49: 369-375. https://doi.org/10.1080/10611932.2016.1283929

Osborne, J. (2008). Best Practices in Quantitative Methods: 8 Mixed Methods Research in the Social Sciences. Sage Research Methods Online. Online ISBN: 9781412995627. Print ISBN: 9781412940658. Doi: 10.4135/9781412995627. Print pages: 125-136.

Perfetti, C., Cao, F. \& Booth, J. (2013). Specialization and universals in the development of reading skill: how Chinese research informs a universal science of reading. Scientific Studies of Reading 17: 5-21.

Plumb, C. (2016). On the possibility of Mandarin Chinese as a Lingua Franca. Journal of Educational Issues 2(2): 48-59. Doi:10.5296/jei.v2i2.9458

Rensburg, I., Motala, S. \& David S.A. (2015). Opportunities and challenges for research collaboration among the BRICS nations. Compare: A Journal of Comparative and International Education 45(5): 814-818. Doi: 10.1080/03057925.2015.1074823

Shen, H.H. (2005). An investigation of Chinese-character learning strategies among non-native speakers of Chinese. System 33: 49-68. Doi:10.1016/j.system.2004.11.001

Stieler-Hunt, C. \& Jones, C. (2019). A professional development model to facilitate teacher adoption of interactive, immersive digital games for classroom learning. British Journal of Educational Technology, 50(1): 264-279. Doi: 10.1111/bje

Sung, K. and $\mathrm{Wu}, \mathrm{H}$. (2011). Factors influencing the learning of Chinese characters. International Journal of Bilingual Education and Bilingualism 14(6): 683-700.

Suk-Han Ho, C. \& Bryant, P. (1997). Learning to read Chinese beyond the logographic phase. Reading Research Quarterly 32(3): 276-289.

Suk-Han Ho, C. and Bryant, P. (1997). Phonological skills are important in learning to read Chinese. Developmental Psychology 33(6): 946-951.

Tan, L.H., Spinks, J.A., Eden, G.F., Perfetti, C.A. \& Siok, W.T. (2005). Reading depends on writing, in Chinese. PNAS 102(24): 8781-8785.

Tř́sková, H. (2017). Acquiring and teaching Chinese pronunciation. In: Kecskes I. (ed.), Explorations into Chinese as a second language. Educational Linguistics, 31. Cham, IL: Springer. https://0-doi-org.oasis.unisa.ac.za/10.1007/978-3-319-54027-6_1 978-3

Tse, S.K., Marton, F., Ki, W.W. \& Loh, E. K.Y. (2007). An integrative perceptual approach for teaching Chinese characters. Instructional Science 35: 375-406. DOI 10.1007/s11251-006-9011-4

Wang, Y. \& Lemmer, E. (2015). "It's a lonely journey". Expiences of students learning Chinese as a foreign language at South African universities. PULA: Botswana Journal of African Studies 29(1): 76-86.

Wang, R. \& Xiang, X. (2016). On the function of mother tongue transfer in English vocabulary acquisition. Theory and Practice in Language Studies 6(11): 2208-2214.

Xianka Ren (2014). Character teaching in TCFL in the English context: dilemma and breakthrough, a discussion based on the perspective of semiotics. Comparative Literature: East \& West 20(1): 144-168. DOI: 1080/25723618.2014.12015482

Yan, J. \& Matthews, S. (2017). Relative clauses in English-Mandarin bilingual children Language transfer and development in Singapore. Chinese Language and Discourse 8(1): $1-17$.

Yang, J., Fox, A.R. \& Jacewicz, E. (2015). Vowel development in an emergent MandarinEnglish bilingual child: a longitudinal study. Child Lang. 42: 1125-1145. 